\title{
Resiliência: nova perspectiva na Promoção da Saúde da Família?
}

\author{
Resilience: a new perspective in health promotion?
}

M aria Glícia Rocha da Costa eSilva N oronha ${ }^{1}$

Paloma SodréC ardoso ${ }^{2}$

Tatiana N emoto Piccoli M oraes ${ }^{2}$

Maria deLourdes Centa ${ }^{3}$

${ }^{1}$ Centro deEducação Ambiental/SM M A,

PrefeituraM unicipal de Curitiba. Av. Manoel Ribas

2727, M ercês. 80810-000

Curitiba PR.

mglicia@gmail.com

${ }^{2}$ Núcleo de Estudos. em

Saúdeda Família,

UniversidadeFederal do

Paraná.

${ }^{3}$ Departamento de

Enfermagem, Universidade

Federal do Paraná.
Abstract Thisdescriptivestudy deals with someconcepts of resilience seeking to understand the concept from the viewpoint of health promotion, one of the basic principles of the Brazilian Family Health Program (FHP). Resilience appeared as a new subject in human sciences and in the health area. In human sciences, resilience means the positive capacity of an individual to construct itself coping with adversities, a dimension more attentive to social conditions. Although there is no consensus with regard to this subject, thereseem to be someaspects rel ated with $\mathrm{H}$ ealth Promotion. We emphasize the modern understanding of $\mathrm{H}$ ealth Promotion in order to illustrate some aspects associated with resilience such as the greater capacity of $\mathrm{M}$ an to decide about the determinants of his health condition. Given that $\mathrm{H}$ ealth Promotion is one of the attributions of the Family Health Program, we contextualized the program emphasizing the action of the health professionals in this area in relation to the subject, seeking to promote health working with resilience. Themulti-professional teams of the Family H ealth Program represent at the same timea network of support and protection for thefamilies, identifying possible risk factors. The emphasis given to the promotion of resilience however should not substitute the public policies for fighting the social inequality and precarious life conditions of part of the population.

Key words Resilience, Health Promotion, Family Health Program
Resumo 0 estudo é descritivo a respeito de alguns conceitos sobre resiliência, buscando um entendimento, considerando os pressupostos da promoção da saúdeno contexto do Programa Saúde da Família (PSF). A resiliência apresenta-sena área das ciências humanas e da saúde como um tema novo. $N$ as ciências humanas, a resiliência representa a capacidade de um indivíduo construir-se positivamente frente às adversidades, procura abranger outras dimensões mais atentas às condições sociais. O bservou-se que não há consenso sobre o tema, mas que este apresenta aspectos concernentes com a promoção da saúde. Destacou-se o entendimento moderno de promoção da saúde de modo a ilustrar aspectos que se relacionam à resiliência, como a ampliação da capacidade dos indivíduos de apropriarem-se dos determinantes das condições de saúde. Considerando que a promoção da saúde é uma das atribuições do PSF, contextualizou-se esse programa, enfatizando a atuação dos profissionais dessa área e sua relação com o tema, buscando a promoção da saúde e trabalhando com a resiliência. A equipe multiprofissional deSaúdeda Família éfator deproteção junto às famílias, identificando possíveisfatores de risco e, ao mesmo tempo, se mostrando como uma rede de apoio edeproteção. A ênfasena promoção da resiliência não deve substituir as políticas de combate à de sigualdade social e condições de vida precárias de alguns sujeitos.

Palavras-chave Resiliência, Promoção da Saúde, Saúde da Família 
Introdução

A resiliência apresenta-se na área das ciências humanas e da saúde como um tema novo. Por essa razão, buscou-se inicialmente elucidar alguns conceitos a respeito desse tema que fossem pertinentes no contexto da Saúde Coletiva. A resiliência caracteriza-se pela capacidade do ser humano responder às demandas da vida cotidiana de forma positiva, apesar das adversidades que enfrenta ao longo de seu ciclo vital de desenvolvimento, resultando na combinação entre os atributos do indivíduo e de seu ambiente familiar, social e cultural. Trata-se de um conceito que comporta um potencial valioso em termos de prevenção e promoção da saúde das populações mas ainda permeado de incertezas e controvérsias. 0 estudo é descritivo sobre a resiliência, o tema da promoção da saúde e o PSF, pretendendo refletir eanalisar a resiliência como nova perspectiva na assistência às famílias no cotidiano da equipe multiprofissional de Saúde da Família.

Buscou-se na extensa bibliografia sobre o tema da resiliência extrair subsídios que pudessem instrumentalizar os profissionais da equipemultiprofissional da Saúde da Família na utilização correta da resiliência como nova perspectiva na promoção da saúde junto às famílias. Entretanto, observou-se que não há consenso sobre o tema, mas que este apresenta aspectos concernentes à promoção da saúde.

0 presente estudo apresenta o conceito deresiliência como uma nova perspectiva para a promoção da saúde da família. Buscou-se destacar o entendimento moderno de promoção da saúde de modo a ilustrar aspectos que se relacionavam à resiliência. A seguir, considerando que a promoção da saúde é uma das atribuições do PSF, realizou-se a contextualização da criação desse programa, enfatizando a atuação dos profissionais dessa área e sua relação com o tema, buscando a promoção da saúde e trabalhando com a resiliência.

\section{Resiliência}

A palavra resiliência origina-se do latim, resílio, re + salio, que significa“"ser elástico". Em 1807, surgiu no cenário científico moderno compondo o vocabulário da Física e da Engenharia, sendo um de seus precursores o cientista inglês Thomas Young ${ }^{1}$. A resiliência de um material é a energia de deformação máxima que ele é capaz de armazenar sem sofrer deformações permanentes. Isto é, a resiliência refereseà capacidade de um material absorver energia sem sofrer deformação plástica ou permanente².
N as ciências humanas, a resiliência representa a capacidade de um indivíduo construir-se positivamente face às adversidades. 0 dicionário de língua inglesa Longman Dictionary of Contemporary English apresenta como defini ção deresiliência: "[...] habilidade de voltar rapidamente para o seu usual estado de saúde ou de espírito depois de passar por doenças e dificuldade" 3. A partir daí, observa-se que vários conceitos teóricos sobre resiliência surgem fundamentados numa variedade de disciplinas como a psicologia, biologia, sociologia, psiquiatria, educação, dentre outras.

A resiliência como foco da temática do desenvolvimento humano em situações de risco vem sendo estudada por vários autores em diversas partes do mundo desdea década de 1970, dos quais destacamos as pesquisas ${ }^{4.9}$ que buscam identificar os fatores de risco e de proteção que contribuem para a adaptação dos indivíduos, subsidiando programas de intervenção e políticas públicas no âmbito da saúde mental, em quea principal preocupação desses pesquisadores reside em identificar fatores que auxiliam as pessoas a manter um desenvolvimento saudável na presença das adversidades.

Percebe-se quea utilização do conceito de resiliêncianos espaçosmédico-psico-social érecente. Esta transposição, inicialmente, aconteceu de forma mecânica, desconsiderando a complexidadeintrínseca ao desenvolvimento humano. Os indivíduos resilientes eram aqueles que, como uma bola de borracha ou uma verga de aço, seriam capazes de sobreviver a prolongadas situações de estresse sem apresentar qualquer tipo de dano definitivo em sua saúde emocional ou competência cognitiva ${ }^{10}$. Atualmente, embora esta concepção ainda seja freqüente nos estudos sobre o tema, o conceito procura abranger outras dimensões, menos deterministas e mais atentas às condições sociais, que propiciaram a emergência do fenômen $0^{3,10}$.

Inicialmente, pensava-se existir condições inatas para resistir e ter imunidade a adversidades estressantes enão setornar vítima. A partir da década de 1990, ampliando os conhecimentos sobre o tema da resiliência, diversos estudiosos $\mathrm{S}^{7,10,11}$ reconhecem a resiliência como um fenômeno comum epresente no desenvolvimento de qualquer ser humano e outros enfatizam a necessidade de cautela no uso naturalizado do termo, sendo freqüentemente referido por processos que explicam a "superação" de crises e adversidades em indivíduos, grupos e organizações. A partir de uma revisão crítica das publicações sobre resiliência no final dos anos noventa, verifica-se que o conceito não apresenta uma definição consensual, sendo caracterizado em termos mais operacionais do que descritivos. 
Autores ${ }^{7}$ 10,11 consideram a resiliência como a capacidade do sujeito, em determinados momentos e de acordo com as circunstâncias, lidar com a adversidade, não sucumbindo a ela, alertando para a necessidade de relativizar, em função do indivíduo edo contexto, o aspecto de superação deeventos potencialmente estressores apontado em algumas definições de resiliência. D efendendo que 0 termo resiliência traduz conceitualmente a possibilidade de superação num sentido dialético, representando não uma eliminação, mas uma ressignificação do problema ${ }^{12}$.

A resiliência surge, então, como estratégia, habilidade válida e competência para se enfrentar as adversidades da vida e, assim, ser capaz de superálas, adaptar-se, recuperar-se, inclusive sen do transformado por elas, participando de uma vida ativa e participativa ${ }^{13}$.

A resiliência ${ }^{14}$ seria resultante da interação entre fatores genéticos e ambientais, os quais, também, oscilam em sua função, podendo atuar como proteção em certos momentos e, em outros, como fator de risco. 0 autor trata a resiliência como uma relativa "resistência" manifestada por al gumas pessoas diantedesituações consideradas potencialmente de risco psicossocial para seu funcionamento e desenvolvimento. Para o autor, é justamente esse caráter relativo que faz com que o fenômeno seja observado em algumas circunstâncias, mas em outrasnão, dependendo da etapa do ciclo vital na qual o sujeito se encontra quando enfrenta a adversidadee do domínio examinado no estudo. Pela mesma razão, fica excluída a possibilidade de se pensar a resiliência como um constructo universal aplicável a todas as áreas do funcionamento humano, pois se as circunstâncias mudam, a resposta da pessoa também pode ser modificada. Ressalta, ainda, que esta "capacidade" para superar as adversidades inclui desde a habilidade da pessoa para lidar com as mudanças que acontecem em sua vida, sua confiança na própria auto-eficácia, até o repertório de estratégias e habilidades deque dispõe para enfrentar os problemas com os quais se depara $a^{14}$.

A concepção da resiliência como a capacidade de recuperar o padrão de funcionamento após experienciar uma situação adversa, sem que, no entanto, deixe de ser atingido por ela, éfeita por Garmezy ${ }^{15}$. Em seus estudos, a ênfase na capacidade do sujeito para retomar os padrões de comportamento habituais que possuía antes de vivenciar a adversidade pressupõe que ela funcionava relativamente bem ao se deparar com a situação negativa e somente a partir deste momento passa a ter dificuldades, mas que algo se produz, levando-a a recuperar sua forma.
Estudos na área de psicologia social junto ao Centro de Estudos e Pesquisas CEPRUA - UFRS ${ }^{16}$ detalham pesquisas sobre fenômenos ligados ao sofrimento emocional de indivíduos e famílias que vivenciam de maneira intensa os processos de exclusão social. Estes estudos ${ }^{16}$ definem resiliência como fenômeno caracterizado por resultados positivos na presença de sérias ameaças ao desenvolvimento da pessoa. Segundo essa autora, a resiliência pode ser observada quando há união familiar, qualidade no relacionamento de pais e filhos, em práticas educativas envolvendo afetos, reciprocidade e equilíbrio de poder. Refere ainda que, nas pesquisas sobre resiliência, a exclusão social e a pobreza têm sido destacadas como adversidades crônicas que podem comprometer o potencial de desenvolvimento dos sujeitos.

A pós estas abordagens sobre resiliência e tendo em vista às características do trabalho em saúde no qual os profissionais preservam um certo grau de autonomia no cotidiano dos serviços, autonomias que são expressas nas definições de prioridades decorrentes dos arranjos institucionais e que representam oportunidades para uma atuação transformadora como produto do saber acumulado, num dado momento histórico servindo a uma determinada lógica de organização das práticas, entende-sequea resiliência possa constituir-se numa possibilidade de intervenção na práxis cotidiana do agir da equipe multiprofissional de Saúde da Famíliaa-18.

Chiesa ${ }^{17}$ refere-seà resiliênciaconceituada como categoria práxica, entendida como patrimônio relacional ecircunstancial capaz defortalecer indivíduos que vivenciam situações adversas de sofrimento emocional e exclusão social. Segundo essa autora, a categoria práxica do agir profissional implica instrumentalizar as famílias a se reconhecerem como importantes no cotidiano de seus integrantes valorizar o patrimônio (conjunto de recursos materiais e relacionais potenciais disponíveis) de que dispõem, resgatar seus direitos sociais, compreender as diferentes fases do ciclo de vida e valorizar o diálogo como ferramenta para exercitar a tolerância e respeitar as diferenças existentes entre seus integrantes.

Neste sentido, dentro da proposta de reorganização das práticas de assistência que orienta 0 PSF, novos e antigos instrumentos de trabalho podem ser incorporados para proporcionar meIhor execução das atividades e facilitar 0 alcance dos objetivos de promoção da saúde junto às famílias. Além da consulta médica e de enfermagem individual, como também na realização de visitas domiciliares e atendimentos coletivos, em educa- 
ção em saúde, a resiliência pode estar sendo utilizada por estes profissionais como mais uma ferramenta na atuação junto às famílias.

Reforçando nossa colocação, importante colaboração nos aponta o estudo dessa autora ${ }^{17}$ ao se referir sobre a valorização do sujeito profissional quando diz ser de crucial importância a re-significação da contribuição da sabedoria, da atitude, dos compromissos e da responsabilidade do profissional como tecnologias necessárias para a construção de práticas transformadoras na superação do modelo biomédico ${ }^{17}$.

Entretanto, os estudos ${ }^{16-18}$ mostram que devemos estar atentos ao viés negativo e reducionista da atenção a saúdeque responsabiliza os indivíduos na superação das adversidades, os quais buscam a sobrevivência numa sociedade desigual como a nossa, desresponsabilizando o Estado de suas obrigações como poder público provedor. Apontam também que devemos fomentar e postular abordagens de promoção da saúde salutares com enfoquenuma ciência quefocalizeas potencialidades e qualidades humanas, as quais exijam tanto esforço, reflexão e seriedade conceitual, teórica e metodológica nos estudos e abordagens de distúrbios e desordens humanas.

\section{Fatores de risco efatores de proteção}

Diversas situações, muitas vezes relacionadas a problemas sociais, podem ser consideradas como fatores de risco e estariam afetando a capacidade de resiliência em indivíduos e famílias 4 . Dentre os diversos exemplos, podemos referir: as condições de pobreza, rupturas na família, vivência de algum tipo de violência, experiências de doença crônica ou aguda do próprio indivíduo ou da família e outras perdas importantes.

Outra questão bastante enfatizada ${ }^{7}$ é a visão subjetiva deum indivíduo sobre determinada situação, ou seja, sua percepção, interpretação e sentido atribuído ao evento estressor é que o classificará ou não como condição de estresse. Os eventos considerados como risco são obstáculos individuais ou ambientais que aumentariam a vulnerabilidade de indivíduos ou família durante o desenvolvimento em seu ciclo de vida; além disso, certos atributos da pessoa têm uma associação positiva com a possi bilidade de enfrentar os fatores de risco no cotidiano, de aproveitar os fatores protetores, deser resiliente, sendo crítico esujeito ativo na sociedade ${ }^{7}$. Neste sentido e considerando-se que as experiências de vida negativas são inevitáveis para qualquer indivíduo, sobressai a questão dos níveis de exposição edos limites individuais de cada um, nos períodos mais críticos do desenvolvimento como a infância, adolescência e terceira idade ${ }^{11}$.

Os fatores protetores possuem quatro funções principais, conforme descritos ${ }^{19}$ : 1) reduzir o impacto dos riscos, fato que altera a exposição da pessoa à situação adversa; 2) reduzir as reações negativas em cadeia que seguem a exposição do indi víduo à situação de risco; 3) estabelecer emanter a auto-estima e auto-eficácia, através de estabelecimento de relações de apego segurança [favor rever a construção] e o cumprimento de tarefas com sucesso; 4) criar oportunidades para reverter os efeitos do estresse.

Alguns autores pesquisados ${ }^{7,11,19}$ referem que os fatores de proteção relacionam-se, em primeira instância, a aspectos orgânicos do indivíduo, em seguida, envolvem aspectos subjetivos que pesarão na forma como o indivíduo vai administrar a situação vivenciada no presentee, posteriormente, envolvem as redes de apoio e amparo parentais ou não que possam se fazer presentes. Enfocam ainda a importância das condições do ambiente, econômicas, psicológicas e familiares, fornecidas pelas relações construídas através das redes de apoio social na comunidade ${ }^{19}$.

Neste sentido, o apoio social construído pelo coletivo contribui para o bem-estar do indivíduo, amortecendo o efeito provocado pelas situações adversas surgidas. Diversas referências documentam os benefícios físicos e psicológicos do apoio social, relatando melhor ajustamento dos sujeitos com apoio social a acontecimentos indutores de "estresse", os quais se recuperam mais rapidamente da doença recentemente diagnosticada, diminuindo o risco de mortalidade a doenças específicas, além de usufruírem qualidade de vida mais satisfatória ${ }^{19-21}$.

Asrelações familiaresfuncionam como promoção da vida e bem-estar social, propiciando condições adequadas de vida, favorecendo o desenvolvimento das potencialidades de cada um e do grupo com respeito "à individualidade ea manutenção do ambiente físico e simbólico favorável às trocas e ao crescimento grupal e pessoal"22.

\section{Programa Saúde da Família (PSF) na atenção básica}

No Brasil, as transformações contemporâneas da sociedade, subseqüentes ao regime militar pós1964, exigiram tanto a crítica sistemática do saber hegemônico-dominante que direcionou as políticas públicas no país, inclusiveno setor saúde, quan- 
to à construção de um saber contra-hegemônico e politicamente efetivo ${ }^{23}$. N essecontexto, ocorreram as discussões decorrentes de grave crise no setor saúde que fortaleceram os movimentos sociais e populares deste período, que abrem caminho para a criação do Sistema Ú nico de Saúde (SUS) e mais tarde, do PSF.

Com a aprovação da Constituição em 1988 e das Leis Orgânicas em 1990, garantiu-se legalmente um sistema público eúnico de saúde, com diretrizes fundamentadas nos princípios de eqüidade, integralidade, universalidade, controlesocial ehierarquização da assistência. Muito cedo, entretanto, movimentos populares, academia e movimentos contra hegemônicos percebem que a escrita do texto constitucional não ésuficiente para o enfrentamento de uma hegemonia sanitária capitalista ${ }^{23,24}$.

Apesar dos avanços alcançados no campo organizacional, com a instituição legal do SUS, ainda continua acentuado o modo predominante de produção dos serviços de saúde, característico da hegemonia sanitária capitalista, aquel es voltados para a doença, sem território definido e centrados no atendimento curativo e assistencial24-26. A luta se estende para alcançar mudanças nas ações de saúde que busquem a maior e melhor resolutividade das ações na sua integralidade, de forma a produzir um considerável efeito na qualidade de vida da população $0^{25}$.

As tentativas de reversão da tendência hegemônica foram de reforçar o controle social, assumir a administração de municípios, elaborar portarias e normas operacionais, criar programas e fomentar mudanças na trajetória de formação de seus profissionais ${ }^{24,26}$. Por volta de 1993 , o M inistério da Saúde iniciou a implementação no Brasil, através da Portaria n 692, do Programa Saúde da Família (PSF), em que este é caracterizado agora como uma estratégia. Dentre as justificativas para sua implementação está o fato de que o modelo assistencial do PSF dá prioridade, além da assistência médica individual, a ações de proteção e promoção à saúde ${ }^{26}$.

O PSF como estratégia surgiu para romper com o modelo hegemônico assistencialista, curativista, medicamentoso e hospitalocêntrico, pautado na compra deserviços e na especialização das ações de saúde. [...] 0 M inistério da Saúde reconhece no Programa de Agentes Comunitários de Saúde e no Programa deSaúdeda Família importanteestratégia para contribuir no aprimoramento e na consolidação do Sistema Ú nico de Saúde, a partir da reorientação da assistência ambulatorial e domiciliar ${ }^{26}$.

A estratégia do PSF foi regulamentada pela Norma Operacional Básica do Sistema Único de
Saúde de 1996 (NOB SUS no 1/96) com o objetivo de provocar a inversão do modelo e, assim, ampliar o conceito de atenção básica, através de incentivos financeiros para sua implantação ${ }^{27}$. Historicamente, sabe-se queo modelo hegemônico de atenção à saú de no Brasil esteve centrado na intervenção dos sinais, sintomas e queixas apresentadas pelo indivíduo, que ao percebê-los procura assistência à saúdee, nesta, o profissional promovea intervenção específica, eliminando ou minimizando o desconforto do usuário. O PSF, ao contrário desse modelo, preconiza que o indivíduo seja visto demaneira integral eacompanhado continuamente em seu modo de viver, que as ações sejam de promoção à saúde e proteção de doenças e, ainda, que a intervenção do setor saúde deva ser para garantir a qualidade de vida da população de sua área de abrangência ${ }^{26,27}$.

Destacamos, nestas políticas públicas, pontos importantes como a estratégia de atuação em vigilância à saúde e atenção continuada à população, ações estas que não devem se restringir ao setor saúde, devendo ser articuladas com diferentes setores a nível local eregional, para intervir nosfatores determinantes e condicionantes do processo saúde- doença. N esta atenção continuada à população, deverá ser considerada a história de vida dos sujeitos, que deverão ser capazes de participar juntamente com a equipe multiprofissional, intervindo no enfrentamento dos problemas de saúde vividos $^{26,27}$. Essa participação deverá ir além da construção da proposta de assistência individual ou coletiva, bem como da representação organizada de sua comunidadenos diferentesníveis do SUS, conferências e conselhos de saúde. D esta forma, 0 PSF passa a se constituir numa estratégia inovadora no cenário dos serviços de saúde, priorizando as ações de promoção, proteção e recuperação da saúde das pessoas e das famílias de forma integral e contínua ${ }^{28}$. Entretanto, a possibilidade de identificar de forma dramática a necessidade de mudança e transformação do estabelecido possibilita ao profissional de saúde, numa leitura sócioantropológica, observar detalhes íntimos da vida familiar, suas dificuldades e possibilidades, e isto vem sendo destacado como princípio central da estratégia do PSF 29.

Estas possibilidade ${ }^{29}$ envolvem dois aspectos; em primeiro lugar, as possi bilidades da família no enfrentamento da doença e de riscos, e o segundo aspecto refere-seàs de intervenções da equipe. Este último aspecto está diretamente relacionado com as condições do serviço, equipamentos, habilidades profissionais, formação permanente da equipe multiprofissional, dentre muitos outros. Entende- 
mos que, somente assim, os profissionais possam estar intervindo junto os usuários que vivem em estado fragilizado, angustiante, frustrante e de impotência diante das dificuldades encontradas, resistindo e criando meios de valorizar a vida, construindo e explicitando o sentido do cuidar, do respeito, da troca, do sorriso, da solidariedade.

Surge então, a necessidade de que os serviços de saúde e seus profissionais sejam maisflexíveis, desvinculados dos procedimentos tradicionais cristalizados no núcleo de suas formações, passando a adotar uma forma de interação inovadora, contextualizada e em consonância com as crenças e valoresdasfamíliasno cenário social epolítico. Além de exigir uma atuação integrada entreos diversos profissionais componentes da equipe multiprofissional, deve haver a interação articulada com as reais demandas e necessidades da comunidade ${ }^{28}$.

As funções e ações desenvolvidas pela equipe multiprofissional, dentro do processo de trabalho na Saúde da Família, vêm sendo distribuídas entre visitas domiciliares, ações programáticas e atendimentos no consultório ${ }^{30}$. Esse autor refere que a estratégia deve trabalhar com a idéia de que "a intervenção no ambiente familiar écapaz de prevenir os agravos à saúde" ${ }^{30}$. Dessa forma, torna-se fundamental a formação e educação permanente da equipe multiprofissional, quer seja a que atue na assistência, no planejamento ou na programação de suas ações.

As ações de saúde buscam solucionar o processo saúde-doença num contexto de família com pressupostos básicos, como o desenvolvimento emocional, a socialização, a organização dos papéis e das relações de seus membros com a comunidade e a preservação do patrimônio ${ }^{28}$. Essa atenção à família permite aos profissionais uma compreensão mais ampla do processo saúde doença, permitindo-Ihes o reconhecimento das necessidades de intervenções para além das práticas curativas ${ }^{25}$.

O PSF apresenta muitos desafios, entre eles 0 de como qualificar e classificar uma família, consolidando as informações provenientes de seus membros, de modo a compreender sua organização. Além disso, ele deve reconstruir as "práxis" humanas, de forma a reinventar maneiras de ser no âmbito familiar e comunitário ${ }^{28}$.

Ao longo do tempo, o PSF vem se mostrando como excelente estratégia de intervenção, encontra-se aberto a propostas inovadoras para melhor atuar junto à comunidade que assiste ${ }^{26-31}$. É neste sentido que visualizamos possibilidades de trabaIhar com a resiliência, utilizada como nova perspectiva de promoção da saúde. A utilização, no PSF, da abordagem focada na resiliência, parece fomentar uma adequada rede de apoio social. Nesse estudo, compreende-se por "rede de apoio social" os recursos estruturais e humanos disponíveis numa localidade e, no caso do PSF, aqueles existentes em sua área de abrangência, para atendimento às famílias em situação de risco social, podendo ser institucionais ou não, os quais destacam-se as unidades de saúde, entidades ligadas à defesa de direitos da criança, como Conselho Tutelar, e outras organizações não governamentais (ONGs) e entidades assistenciais da sociedade civil, associações comunitárias locais (moradores, bairro), abrigos e albergues municipais, escolas e creches, centros de juventude ou educacionais, escolas, programas de fornecimento de alimentação, esportes e lazer, dentre outros. Essa abordagem pode contribuir para afastar e amenizar os efeitos da adversi dade, como também gerar novos mecanismos protetores nas comunidades em que está inserida, ao enfocar aspectos interacionais de vínculo e de confiança, trazendo à tona a singularidade e a delicadeza das relações ditas microssociais de promoção em saúde ${ }^{31,32}$. Entretanto, vale ressaltar quea abordagem utilizando a resiliência não pode ser distorcida para sustentar o discurso de superação individual, desagregada das condições de desigualdades sociais, econômicas e das relações macrossociais do sistema, subestimando circunstâncias de vida penosas das pessoas.

\section{Promoção da saúde}

A promoção da saúdetem setornado cada vez mais presente na prática dos profissionais de saúdee, na atualidade, é incluída como componente de destaque na organização de novos modelos de prestação de serviços no campo da saúde pública, como é o caso do Programa de Saúde da Família. A noção de promoção à saúde foi introduzida por Leavell e Clark, em 1976, no desenvolvimento do modelo denominado história natural da doença, que era aplicado a partir do grau de conhecimento do curso de cada doença, definindo-se em três níveis de prevenção: o primário, secundário e terciário ${ }^{33}$.

O conceito moderno de promoção da saúde e sua prática foram bastante estudados nos últimos vinte anos, principalmente no Canadá, Estados Unidos e países da Europa O cidental. Entre 1986 e 2000, foram realizadas importantes conferências sobre a promoção da saúde a nível internacional, dentre elas: Ottawa (1986), Adelaide (1988), Sundsval (1991), Bogotá (1992), Jakarta (1997) e no M éxico (2000) ${ }^{34}$.

Após a Carta de Ottawa, desenvolveu-se uma 
nova forma de intervenção em saúde, a qual passa a enfocar a capacitação das populações para, no confronto com os riscos, conseguir um rápido restabelecimento, com o mínimo de danos causados pela exposição aos fatores de risco ${ }^{34}$. Assim, a promoção da saúde envolve um vasto conjunto de fatores que incluem adaptações ambientais e comportamentais, conseguidas através de estratégias educacionais, mantendo como foco a ação sobre as pessoas ${ }^{35}$.

$\mathrm{NaD}$ eclaração de Jakarta, está descrito que, para se ter saúde, são necessários pré-requisitos como a paz, abrigo, instrução, segurança social, relações sociais, alimento, renda, um ecossistema estável, uso sustentável dos recursos naturais, justiça social, respeito aos diretos humanos e eqüidade ${ }^{26}$.

Dessa forma, o conceito de promoção da saúde deve ser entendido como um novo modo de compreender a saúde e a doença e uma nova forma dos indivíduos e da coletividade obterem saúde. A promoção, diferentemente da prevenção, caracterizase por um conjunto de intervenções que têm como meta a eliminação permanente ou pelo menos duradoura da doença, tentando-se eliminar suas causas mais básicas e não apenas evitar que se manifestem ${ }^{35}$. Por outro lado, é importante atentar para as armadi lhas do pensamento e interesses dominantes que estimulam a responsabilização dos sujeitos, como se percebe nos discursos dentro do contexto da chamada terceira revolução da saúde, somada a abstenção das responsabilidades do Estado, voltada à redução da racionalização dos custos, o que muitas vezes significa a precarização dos serviços ${ }^{35}$.

O conceito moderno de promoção da saúde deve implicar atividades voltadas tanto a grupos sociais como a indivíduos, por meio de políticas públicas abrangentes, em relação ao ambientefísico, social, político, econômico e cultural e do esforço comunitário, na busca de melhores condições de saúde ${ }^{36}$. Desta forma, entendemos que estratégias de promoção da saúde podem provocar emodificar estilos devida, bem como as condições sociais, econômicas e ambientais que determinam a saúde, implicando um enfoque prático para a obtenção de maior eqüidade em saúde.

A promoção da saúde implica um novo paradigma de saúde e doença, além de uma mudança social significativa em direção a uma sociedade independente do princípio da produção para o mercado e para o lucro ${ }^{36,37}$. Este contemporâneo movimento pela promoção da saúde tem revelado a resiliência como um conceito importantenessa área de conhecimento. Por ser um tema recentemente incorporado ao campo da saúde, encontra-se em fase de construção, discussão e debate, principal- mente por não existir ainda um consenso em relação à definição do termo. Contudo, mesmo em face da incompletude, a resiliência foi instaurada no campo da promoção da saúde, discutindo-se hojea ampliação do conceito para além dos indivíduos, por intermédio de expressões como escolas resilientes ou comunidades resilientes ${ }^{36,37}$.

Muitos são os conceitos sobre resiliência e como esta influencia o comportamento humano frente às condições da vida. Contudo, deve-se ressaltar que existem dois aspectos a serem considerados que auxiliam essa conduta: "a capacidade de resistência frente às situações adversas e a capacidade de construção positiva que garante as condições de enfrentamento"31.

N esta compreensão, a resiliência ${ }^{31}$ éconstituída de acordo com as relações que são estabelecidas entreo indivíduo e o meio; entretanto, não podendo desconsiderar os aspectos individuais, familiares, sociais eculturais. A identificação edesenvolvimento de características resilientes em pessoas ou grupos podem tornar-se um instrumento de restabelecimento dos membros que compõem as famílias, permitindo-Ihes a buscar novas condições de vida para que não fiquem acomodados face à adversidadet. Destemodo, pode-sepensar a resiliência como nova perspectiva que contribui para as ações do PSF, segundo os princípios norteadores deste, dentre eles, a promoção da saúde. Ela não está enfocada nas ações desenvolvidas pelos profissionais que atuam no PSF enem nas construídas pelas instituições de formação profissional.

\section{Conclusão}

Resiliência éum conceito complexo eamplo, enfocado em vários contextos e abordagens. N essesentido, compreendemos, juntamente com as considerações dos vários autores pesquisados, a resiliência como o conjunto de processos sociais e intrapsíquicos que possibilitam o desenvolvimento de uma vida sadia, mesmo vivendo em um ambientenão sadio ${ }^{10}$. Esta resulta da combinação entre os atributos da pessoa e seu ambiente familiar, social ecultural. D estemodo, a resiliência não pode ser pensada como um atributo que nasce com 0 ser humano, nem que ele adquire durante seu desenvolvimento, mas sim como um processo interativo en trea pessoa eseu meio, considerado como uma variação individual em resposta ao risco, sendo que os mesmos fatores causadores de estresse podem ser experienciados deformas diferentes por pessoas diferentes, não sendo a resiliência um atributo fixo do sujeito/indivíduo ${ }^{4-9}$. 
Falar sobre resiliência efatores de proteção para sua promoção exige um olhar sensível à pluralidade cultural que caracteriza a existência humana. Os fatores de proteção estão associados a resiliência, visto que buscam estratégias para incrementar as características pessoais e condição de vida que são fundamentais para a tentativa de Promoção da Saúde ${ }^{31}$.

A equipe multiprofissional de saúde da família pode tornar-se fator de proteção junto às família, identificando possíveis fatores de risco e, ao mesmo tempo, se mostrando como uma rede de apoio/fator de proteção, $711,19,31$. Ao exercer esse papel, busca fortalecer a resiliência, promovendo saúde. Para tanto, são necessários recursos materiais e estruturais dos serviços públicos de saúde, de formação e educação básica epermanente dos profissionais para planejamento e programação das ações. A experiência da resiliência écompatível com a existência de conflitos que produzem comportamentos freqüentemente considerados desviantes pela sociedade ${ }^{4 \cdot 9}$.

Enten de-se que a resiliência apresenta uma característica diferenciada, que pode ser utilizada pela área da saúde, que é o caráter de enfrentamento e construção positiva frente à adversidade, possi bilitando que os indivíduos participem de uma vida ativa e participativa, com a capacidade de se transformar, tornando-se um sujeito crítico frente às condições que propiciaram o desenvolvimento da resiliência. Visto dessa forma, não se torna um ser passivo e conformado frente às adversidades encontradas, o queédiferente deuma adaptação pura e simples, que reproduz os interesses dominantes.

O PSF auxilia as famílias e indivíduos no enfrentamento de situações de risco principalmente pela possibilidade da construção, de acolhimento e de vínculo, independente de queixas agudas recorrentes. Entretanto, torna-sefundamental 0 aprimoramento das políticas públicas e de ação social, para que não sejam apenas as disponibilidades subjetivas ou a generosidade individual de membros da equipe multiprofissional que possam vir a garantir 0 atendimento ${ }^{32}$. M esmo com a visualização dos avanços que a resiliência possa oferecer, quando utilizada como uma nova perspectiva de promoção da saúde, deve-se ter a preocupação de não subestimar circunstâncias penosas de vida ea desigualdade social.

$\mathrm{N}$ as sociedades ocidentais contemporâneas, motivadas por valores extremamente individualistas, há um risco de que essa linha de pensamento possa nos levar a retroceder para a era de $\mathrm{Da}$ rwin, na qual a sobrevivência era dos mais capazes $^{4-9}$. Daí a importância de pesquisas futuras dentro da perspectiva humanista do desenvolvimento do ser humano e da saúde coletiva, levando em consideração a ética, eqüidade, ambientes humanos sustentáveis e equilíbrio ecológico.

\section{Colaboradores}

M L Centa, PS Cardoso e TNP M oraes participaram igualmente da revisão bibliográfica, concepção teórica, elaboração e redação do artigo. 


\section{Agradecimentos}

Agradecemos à Profa. Dra. M aguida Costa Stefanelli, pela revisão do artigo e pela colaboração na elaboração do título.

\section{Referências}

1. Timosheibo SP. History of strength of materials. Mineola, NY: Dover Publications; 1983.

2. Silva Jr. JF. Resistência dos materiais. São Paulo: Ao Livro Técnico; 1972.

3. Summers D. Longman dictionary of contemporary English. New York: Longman Group Ltd.; 1995.

4. Andrade AM BA. Resiliência enquanto modelo de atuação na estratégia de intervenção do Programa Saúde da Família - PSF [dissertação]. Fortaleza (CE): Faculdade de M edicina, Universidade Federal do Ceará; 2001.

5. Yunes MAM, Szymanski H. Resiliência: noção, conceitos afins e considerações críticas. In: Tavares J, organizador. Resiliência e educação. São Paulo: Cortez; 2001. p. 13-42.

6. Tavares J. A resiliência na sociedade emergente. In: Tavares J, organizador. Resiliência e educação. São Paulo: Cortez; 2001. p. 43-75

7. Yunes MAM. Psicologia positiva e resiliência: o foco no indivíduo e na família. Psicol. estud. 2003; 8 (num. esp.): $75-84$.

8. Rutter M. Resilience: some conceptual considerations. Journal of Adolescent $\mathrm{H}$ ealth 1995; 14:626-631.

9. Silber $T, M$ addaleno M. La resiliencia, la promoción de la salud y el desarrollo humano. Adolescência Latino-Americana 2001; 2(3):125.

10. Yunes MAM . A questão triplamente controvertida da resiliência em famílias de baixa renda [tese]. São Paulo (SP): Pontifícia Universidade Católica de São Paulo; 2001.

11. Pinheiro DPN. A resiliência em discussão. Psicol. estud. [periódico na Internet] 2004 [acesso 2005 ago 05];9(1). Disponível em: http://www.scielo.br/scielo. php?script=sci_arttext $\&$ pid $=$ S1413-7372200400010000 $9 \& \operatorname{lng}=e n \& n r m=i s 0$

12. Junqueira M FP, Deslandes SF. Resiliência e maus tratos à criança. Cad Saúde Pública [periódico na Internet] 2003 [[acessado 2005 ago 23]. Disponível em: http:/ /www.scielo.br/pdf/csp/v19n1/14923.pdf

13. Grünspun HE. Conceitos sobre resiliência. [site na Internet]. 2003 [acessado 2005 nov 8]. Disponível em: http://www.crmmt.cfm.org.br/revista/bio10v1/ RevistaBioética.pdf

14. Rutter M. Resilience concepts and findings: implications for family therapy. Journal of Family Therapy 1999; 21:119-144.

15. Garmezy N. Children in poverty: resilience despite risk. Psychiatry 1993; 56:127-136.

16. Cecconello AM. Resiliência e vulnerabilidade em famílias em situação de pobreza: fatores de risco e proteção [tese]. Porto Alegre (RS): Faculdade de Psicologia, Universidade Federal do Rio Grande do Sul; 2003.

17. Chiesa AM. Autonomia e resiliência: categorias para 0 fortalecimento da intervenção na atenção básica na perspectiva da Promoção da Saúde [tese de livre docência]. São Paulo (SP): USP; 2005.

18. M erhy EE. A perda da dimensão cuidadora na produção da saúde. In: Campos CR, Malta D, Reis A, organizadores. Sistema Único de Saúde em Belo Horizonte: reescrevendo o público. São Paulo: Xamã; 1998. p.103-120. 
19. Pesce R, Assis SG, Santos N, Oliveira RVC. Risco proteção: em busca de um equilíbrio promotor de resiliência. Psicologia: Teoria e Pesquisa 2004; 20(2):135143.

20. Nunes M. Apoio social na diabetes. Millenium [periódico na Internet] 2005 [acessado 2005 nov 19]. Disponível em: http://www.ipv.pt/millenium/Millenium31/10.pdf

21. Silva OPU. A importância da família no desenvolvimento do bebê prematuro. Psicologia: Teoria e Prática [periódico na Internet] 2002 [acessado 2005 nove 9]; 4 (2):[cerca de 10 p.]. Disponível em: http://www. mackenzie.br/fileadmin/Editora/Revista_Psicologia/ Teoria e Pratica Volume 4 - Numero 2/v4n2 art1

22. Elsen I. Cuidado familial: uma proposta inicial de sistematização conceitual. In: Elsen I, M arcon SS, Santos MR. 0 viver em família e sua interface com a saúde e a doença. M aringá: Eduem; 2002. p.11-27.

23. Dâmaso R. Saber e práxis na reforma sanitária: avaliação da prática científica no movimento sanitário. In: Teixeira SF. Reforma sanitária: em busca de uma teoria. São Paulo: Cortez; Rio de Janeiro: Abrasco; 1989. p. 61-79.

24. Da Ros MA. Estilos de pensamento em saúde pública: um estudo da produção da FSP e Ensp-Fiocruz, entre 1948 e 1994, a partir da epistemologia de Ludwik Fleck [tese]. Florianópolis (SC): CCE-UFSC; 2000.

25. Senna MCM, M ello ALR, Bodstein R. A Estratégia Saúde da Família no DLIS - M anguinhos. In: Bodstein LZ, Zancan L, M arcondes WB. Promoção da saúde como caminho para o desenvolvimento local: a expe riência em Maguinhos. Rio de Janeiro: Abrasco/Fiocruz; 2002. p.15-37.

26. Brasil. Ministério da Saúde. Portaria no 1.886 de 18 de dezembro de 1997. Brasília: M inistério da Saúde; 1997.

27. Peres EM. Saúde da Família: conceitos, diretrizes e me todologia: treinamento introdutório em gestão. Rio de Janeiro: Centro Biomédico, UERJ; 1999.

28. Cianciarullo TI. Compreendendo a família no cenário de uma nova estratégia de saúde. In: Cianciarullo TI, Gualda DM R, Cunha ICKO, Silva GT. Saúde na família e na comunidade. São Paulo: Robe Editorial; 2002. p. 17-37.

29. Vasconcelos MPC. Reflexões sobre a Saúde da Família. In: Mendes EV. A organização da saúde no nível local. São Paulo: Hucitec; 1998. p. 155-172.
30. Franco TB, M erhy EE. Programa Saúde da Família (PSF): contradições de um programa destinado à mudança do modelo tecnoassistencial. In: Merhy EE, $M$ agalhães Júnior EM, Rimoli J, Franco TB, Bueno WS, organizadores. 0 trabalho em saúde: olhando e experienciando o SUS no cotidiano. 2a ed. São Paulo: Hucitec; 2004. p. 55-124.

31. Andrade AMBA, Bucher JSFN. Resiliência à luz do sujeito coletivo: uma contribuição ao Programa Saúde da Família. In: Lefévre F, Lefévre AMC, organizadores. 0 discurso do sujeito coletivo: um novo enfoque em pesquisa qualitativa. Caxias do Sul: EDUCS; 2003. p. 217-232.

32. Celia S. Promoção da saúde e resiliência. In: Fichtner $\mathrm{N}$, organizador. Prevenção, diagnóstico e tratamento dos transtornos mentais da infância e da adolescência: um enfoque desenvolvimental. Porto Alegre: Artes M édicas; 1997. p. 21-25.

33. Leavell HR, Clark EG. M edicina preventiva. São Paulo: McGraw-Hill; 1989.

34. Ferreira JR, Buss PM. O que o desenvolvimento local tem a ver com a promoção da saúde? In: Bodstein LZ, Zancan L, M arcondes WB. Promoção da saúde como caminho para o desenvolvimento local: a experiência em M aguinhos. Rio de Janeiro: Abrasco/Fiocruz; 2002. p.15-37.

35. Matos M G. Psicologia da Saúde, Saúde Pública e Saúde Internacional. Análise Psicológica 2004; 3 (XXII):449-462.

36. Buss PM. Promoção da saúde e qualidade de vida. Cien Saude Colet [periódico na Internet] 2000 [acessado 2005 ago 23]; 5(1):[cerca de 15 p.]. Disponível em: http://www.scielo.br/pdf/csc/v5n1/7087.pdf

37. Lefévre $F$, Lefévre $A M C$, organizadores. 0 discurso do sujeito coletivo: uma abordagem metodológica em pesquisa qualitativa. Caxias do Sul: EDUCS; 2000.

Artigo apresentado em 28/09/2006

A provado em 07/02/2007

Versão final apresentada em 16/02/2007 